\title{
An Alkyne Linchpin Strategy for Drug:Pharmacophore Conjugation: Experimental and Computational Realization of a meta-selective Inverse Sonogashira Coupling
}

Sandeep Porey, ${ }^{1,+}$ Xinglong Zhang, ${ }^{2, \dagger}$ Suman Bhowmick, ${ }^{1}$ Vikas Kumar Singh, ${ }^{1}$ Srimanta Guin, ${ }^{1, *}$ Robert S. Paton, ${ }^{2,3, *}$ and Debabrata Maiti ${ }^{1, *}$

${ }^{1}$ Department of Chemistry, Indian Institute of Technology Bombay, Powai, Mumbai 400076, India

${ }^{2}$ Chemistry Research Laboratory, University of Oxford, Mansfield Road, Oxford, OX1 3TA, UK

${ }^{3}$ Department of Chemistry, Colorado State University, Fort Collins, Colorado 80523, USA

${ }^{\dagger}$ These authors contributed equally to this work

Email: dmaiti@iitb.ac.in (DM)

Email: robert.paton@colostate.edu (RSP)

Email: srgnchem@gmail.com (SG)

\begin{abstract}
The late-stage functionalization (LSF) of pharmaceutical and agrochemical compounds by the site-selective activation of $\mathrm{C}-\mathrm{H}$ bonds offers immediate access to diverse structural analogs and expands the accessible chemical space. We report an C-H functionalization LSF strategy that hinges on the use of an alkyne linchpin to assemble conjugates of $\mathrm{sp}^{2}$-rich marketed pharmaceuticals and agrochemicals with $\mathrm{sp}^{3}$-rich $3 \mathrm{D}$-fragments and natural products. This is accomplished through a template-assisted inverse Sonogashira reaction that displays high levels of selectivity for the meta-position. This protocol is also amenable to distal structural modifications of $\alpha$-amino acids. The transformation of alkyne functionality to other functional groups further highlights the applicative potential. Computational and experimental mechanistic studies shed light on the detailed mechanism. Turnover-limiting 1,2-migratory insertion of the bromoalkyne coupling partner occurs after relatively fast $\mathrm{C}-\mathrm{H}$ activation. While this insertion occurs unselectively, regioconvergence results from one of the adducts undergoing a 1,2-trialkylsilyl
\end{abstract}


migration to form the alkynylated product. A heterobimetallic $\mathrm{Pd}-\mathrm{Ag} \mathrm{TS}$, which is essential for product formation, is explicitly implicated in the $\beta$-bromide elimination step. 
The direct functionalization of unactivated $\mathrm{C}-\mathrm{H}$ bonds continues to challenge chemists and inspire new chemistry. ${ }^{1,2}$ As the synthetic toolbox of $\mathrm{C}-\mathrm{H}$ functionalization reactions continues to grow, concerted effort has focused on harnessing broad functional group compatibility to accommodate the demands of complex molecule synthesis. ${ }^{3-5}$ For medicinal chemistry, emerging $\mathrm{C}-\mathrm{H}$ functionalization methods present opportunities to explore chemical space inaccessible by conventional synthetic processes. ${ }^{6}$ The recognition of $\mathrm{C}-\mathrm{H}$ bonds as sites for potential diversification expands the availability of late-stage functionalization (LSF) strategies and enables the development and diversification of biologically active molecules without resorting to de novo synthesis. ${ }^{7,8}$ Furthermore, LSF facilitates the exploration of structure-activity relationships, the optimization of physical properties, and enables new reaction vectors to be explored. However, a major challenge towards the widespread adoption of LSF by $\mathrm{C}-\mathrm{H}$ bond functionalization of pharmaceutical compounds is the requirement for precise control over site-selectivity: This challenge is compounded by the abundance of heteroatoms in druglike fragments, ${ }^{9}$ as these Lewis basic sites bind competitively with catalysts, resulting in potentially undesirable site-selectivity or catalyst poisoning. ${ }^{10}$

Significant advances in the selective post-synthetic modification of pharmaceutical compounds have been accomplished by chelation assisted ortho-functionalization. ${ }^{7,8,11,12}$ In contrast, meta and para $\mathrm{C}\left(s p^{2}\right)-\mathrm{H}$ functionalizations ${ }^{13-21}$ are less well-developed for this purpose. Strategic access to alternative regioisomers via site-selective $\mathrm{C}-\mathrm{H}$ functionalization would provide an entry to alternative spatial arrangements of medicinally-important functionalities and an expanded chemical space. ${ }^{22}$ The same logic holds true for the structural diversification of $\alpha$-amino acids, which forms the basis of various bioactive oligopeptides. ${ }^{23}$ We were therefore intrigued by the prospect of developing LSF protocols harnessing meta $\mathrm{C}\left(s p^{2}\right)-\mathrm{H}$ functionalization and a 
subsequent alkynylation reaction via an inverse Sonogashira cross-coupling with haloalkynes. ${ }^{24}$ The alkyne functionality provides a rigid and versatile spacer group that permits broad exploration of chemical space through LSF. ${ }^{25}$ For example, an acetylene group can be covalently linked to ketones by a simple nucleophilic addition, such that carbonyl-containing $\mathrm{sp}^{3}$-rich natural product fragments can be conjugated to (hetero)aromatic fragments (Fig. 1). Through this coupling reaction, a wide range of pharmaceutically relevant ketones, including biologically active compounds e.g. estradiol or natural products e.g. menthol, could be covalently attached to various drug-molecules. This transformation also provides direct access to structural modifications of $\alpha$ amino acids such as phenylalanine. However, state-of-the-art protocols for $\mathrm{C}\left(s p^{2}\right)-\mathrm{H}$ alkynylation are currently restricted to a narrow range of alkyne variants, with silyl acetylenic derivatives displaying unique reactivity as coupling partners. ${ }^{26-31}$ The exploration of broader alkyne scope is therefore an essential step in developing a meta-selective conjugation protocol of aromatic drugs with 3D-pharmacophores. 


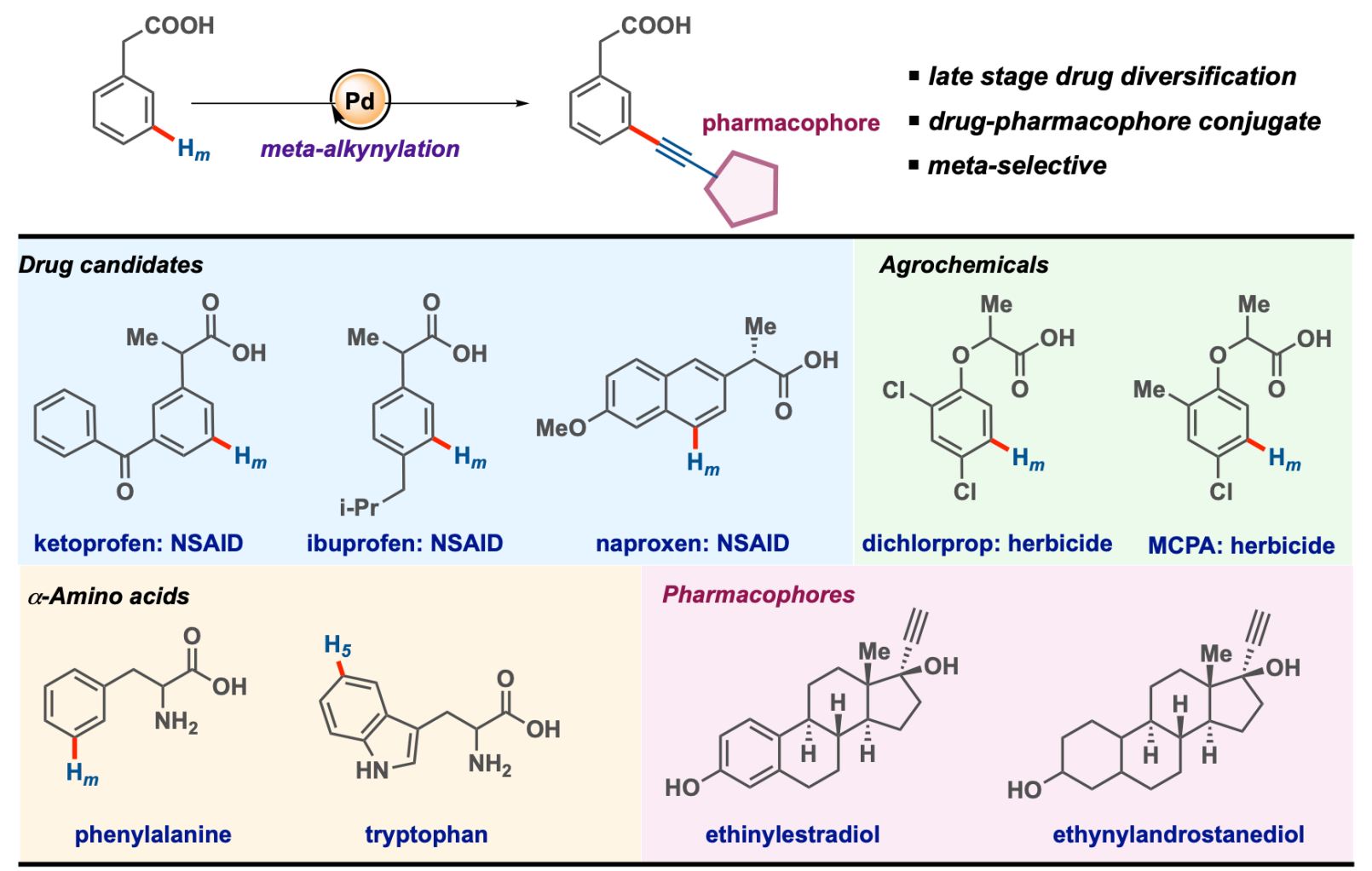

Fig. 1| Linchpin approach for diversification through the conjugation of $\mathbf{s p}^{2}$-rich aromatic and 3D fragments.

\section{Results and Discussion}

Optimization of reaction parameters. The inverse Sonogashira coupling of 3-methyl substituted benzyl sulfonate ester $\mathbf{1 a}$ with triisopropyl acetylene bromide $\mathbf{1 b}$ was explored to optimize reaction parameters. A pyrimidine based meta-directing group (DG) was employed due to its efficacy as a strong $\sigma$-donating and $\pi$-accepting ligand, contributing to its success in accomplishing different functionalizations. ${ }^{32-34}$ An oxidant such as a silver salt is required to regenerate the active Pd catalyst after each catalytic cycle. ${ }^{35}$ Accordingly, $m$-alkynylation was carried out with $\mathrm{Pd}(\mathrm{OAc})_{2}$ as catalyst in the presence of $\mathrm{N}$-Ac-Gly ligand and AgOAc oxidant. Hexafluoroisopropanol (HFIP) solvent has been used previously to promote distal $\mathrm{C}\left(s p^{2}\right)-\mathrm{H}$ functionalization, however, we 
observed no reactivity under these conditions. ${ }^{36}$ In contrast, with a fluorinated aprotic solvent, benzotrifluoride, formation of the desired $m$-alkynylated product 1 was observed, in poor yield but with excellent selectivity. Persisting with benzotrifluoride as solvent, systematic alterations of different reaction parameters showed that $\mathrm{AgOAc}$ and $\mathrm{Cu}(\mathrm{OAc})_{2}$ were both essential. Gratifyingly, the yield of the $m$-alkynylated product could be further increased switching to 1,4-dioxane as solvent. Pyridine, quinoline and nitrile based meta DGs ( $\mathbf{D G}_{\mathbf{2}}-\mathbf{D G}_{\mathbf{8}}$, Table 1) were inferior to pyrimidine (DG1, Table 1). Full details of these optimization studies are in Supplementary Information (see SI 2.2.a)

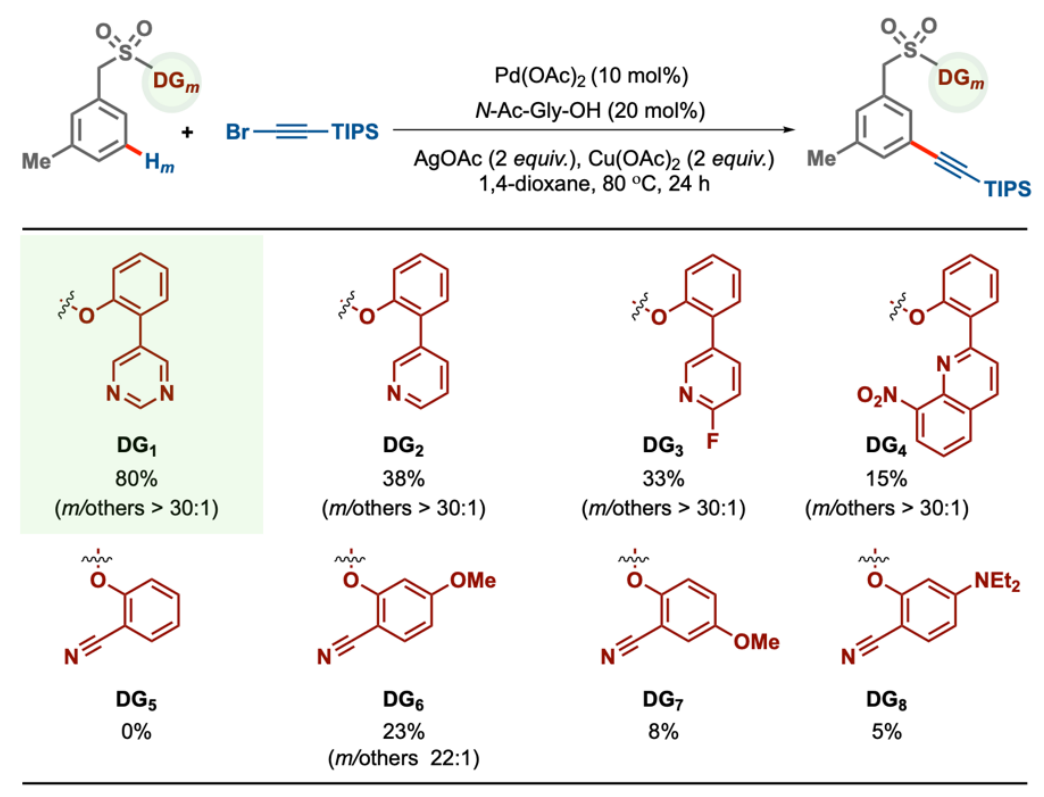

Table 1| Evaluation of Directing Groups

Scope of meta-selective $\mathbf{C}-\mathbf{H}$ alkynylation. The optimized reaction conditions were used to explore reaction scope. Strikingly, meta-selective $\mathrm{C}-\mathrm{H}$ alkynylation tolerates benzyl sulfonyl esters with electronically diverse aromatic substituents in ortho, meta and para positions. The anticipated alkynylated products were obtained in synthetically useful yields along with excellent meta-selectivity (Fig. 2). More importantly, reactive chloro- (9), bromo- (3), and ester (6) 
functional groups were left untouched, while a thiophene moiety at the meta-position (15) was also a viable substrate. Variation of the alkyl group connecting the DG was then explored (Fig. 3). Substituted and unsubstituted arenes with ethyl, propyl, butyl chains provided exclusively monoalkynylated products in good yields and selectivity (16-21).

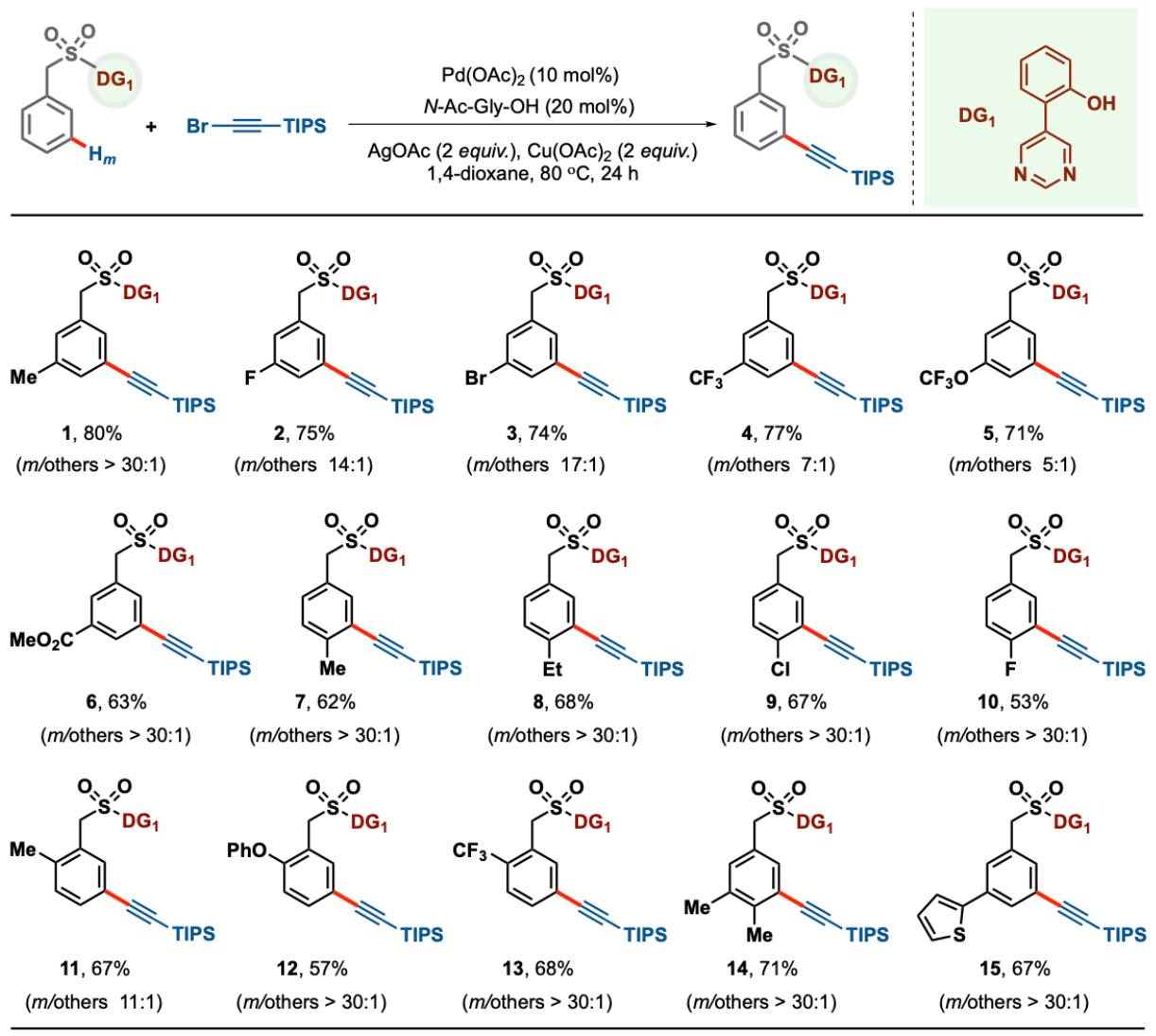

Fig. 2| Scope of the reaction with benzylsulfonyl esters.

The robustness of the protocol was demonstrated using phenyl acetic acids and benzyl silyl ethers as substrates (Fig. 3). In all cases, a range of substituents with varying electronic and steric properties were compatible (22-37). Phenyl (30) and cyclopropyl (31) groups were well tolerated at the $\alpha$-position of phenylacetic acids. Intriguingly, the present protocol provides access to diversified unnatural amino acids. Meta-selective alkynylated product $\mathbf{3 2}$ was obtained from the phenylalanine derivative in high yield and selectivity, while C5 alkynylation of the tryptophan 
derivative gave $\mathbf{3 3}$ in excellent selectivity. To the best of our knowledge, this constitutes the first example of an indole alkylation at the distal $\mathrm{C} 5$ position by a directed $\mathrm{C}-\mathrm{H}$ activation.

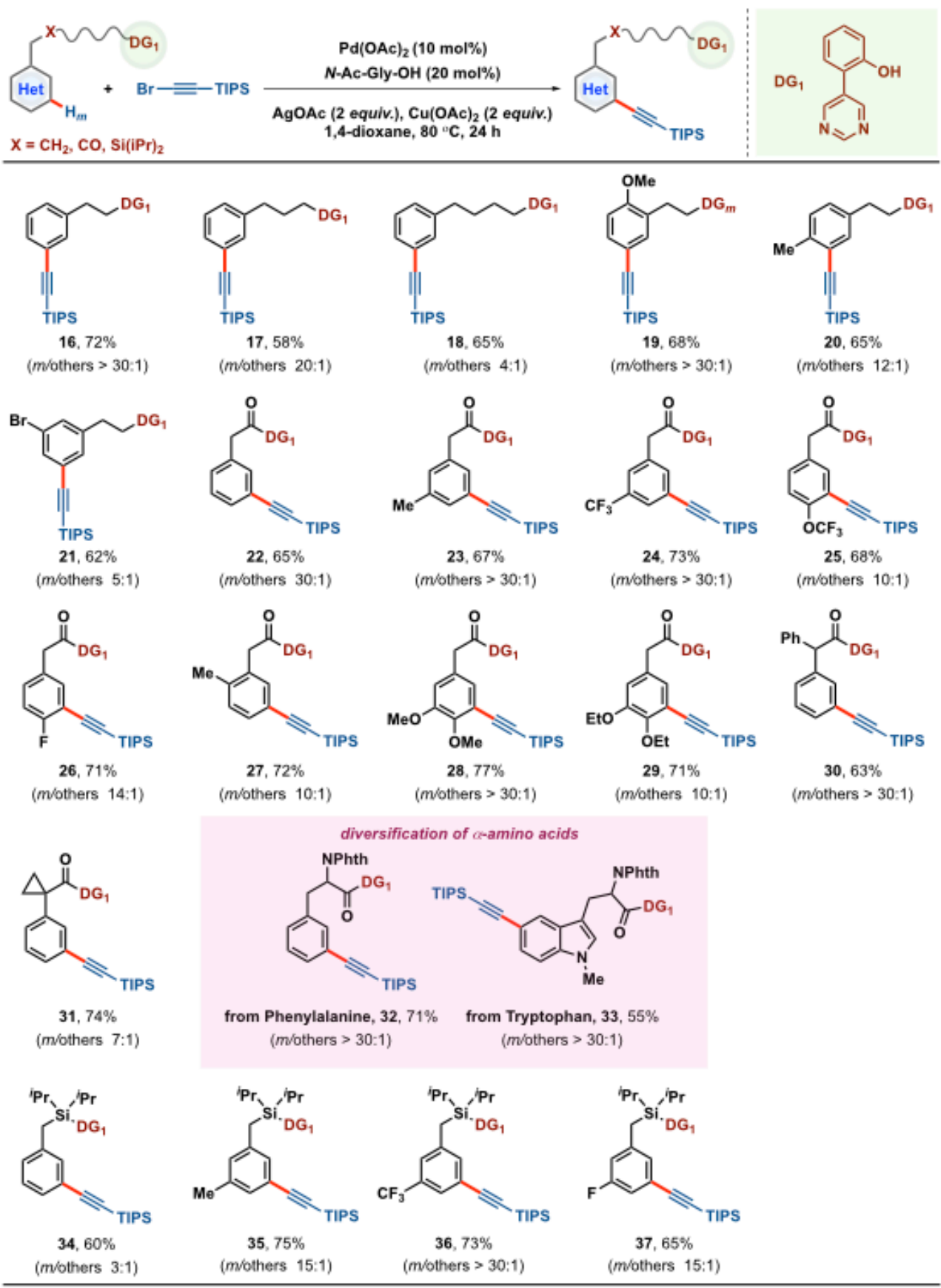

Fig. 3| Scope of the reaction with variable chain-length tethered scaffolds, phenylacetic acids and benzylsilyl ethers. 
We next investigated generality with respect to the alkyne (Fig. 4). Propargyl silyl ethers prepared by nucleophilic addition to a series of ketones were reacted with arenes with different linker systems. The alkynyl bromide derived from methone (itself of pharmaceutical relevance) underwent facile reaction with different scaffolds in good yields and selectivities $(\mathbf{3 8}, \mathbf{4 0}, \mathbf{4 5}, \mathbf{4 7 -}$ 50). Similarly, meta-alkynylation carried out with alkynyl bromides obtained from the bicyclic ketone 2-norbornanone (39, 44), cyclohexanone derivative (42) and larger ring system cyclooctanone (43) proceeded smoothly to provide synthetically useful yields of their corresponding products. Notably, a phenol derivative was a competent substrate, providing metaselective product 40, the DG overcoming any innate electronic bias towards ortho functionalization. Androstanediol, a potent $\mathrm{GABA}_{\mathrm{A}}$ receptor, ${ }^{37}$ could also be conjugated selectively at the meta position (46), regardless of the steric hindrance exerted by the bulky steroid. The (protected) diol product contains the ethynylandrostanediol fragment, an orally active analogue of 17-substituted androstanediol used to treat cancer. When phenyl acetylenic bromide was used as the alkynylating agent, the reaction failed to proceed. The same observation was noted with triisopropyl acetylene also. The incompatibility of these substrates was subsequently rationalized computationally (see Supplementary Information, section 2.6.10 and SI 2.6.11).

Pharmaceutical and agrochemical LSF was then examined using this newly developed protocol (Fig 5). To this aim, marketed nonsteroidal anti-inflammatory drugs such as ketoprofen (51), ibuprofen (52), naproxen (53), baclophen (57) were transformed to their $m$-alkynylated derivatives in excellent selectivity with triisopropyl acetylene bromide. Phenoxy based agrochemicals and drugs such as dichlorprop (herbicide, 54), clofibric acid (lipid lowering agent, 55) and MCPA (herbicide, 56) were similarly functionalized. 


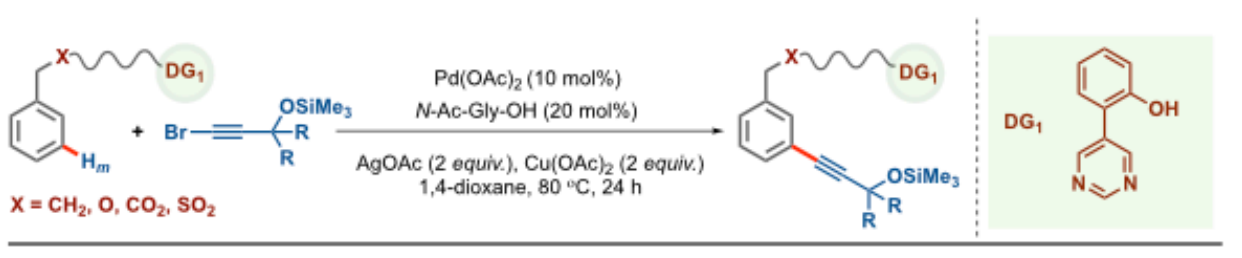

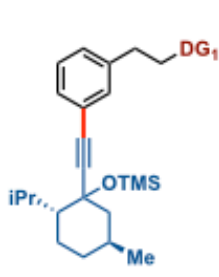

$38,65 \%$

(m/others 20:1)

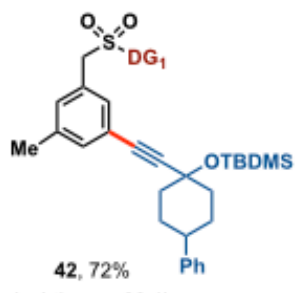

(m/others > 30:1)
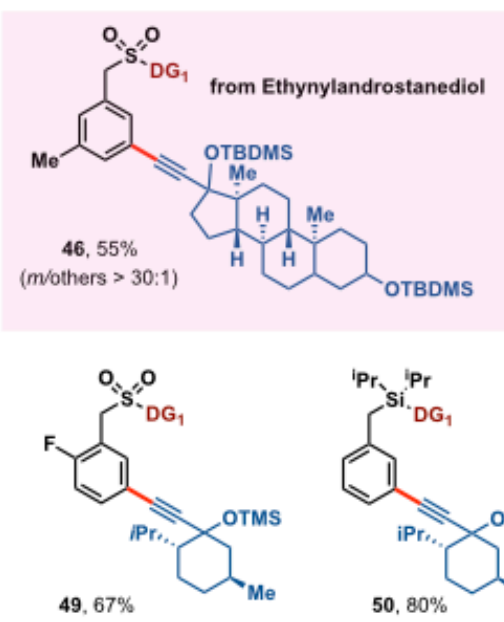

( $m /$ others > 30:1)

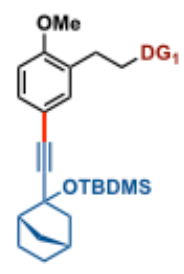

$39,62 \%$
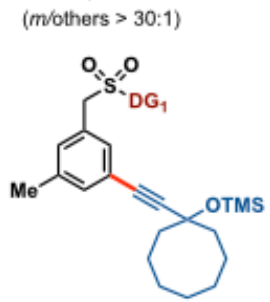

$43,62 \%$

(m/others 12:1)

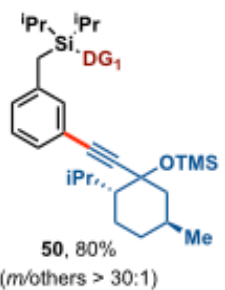

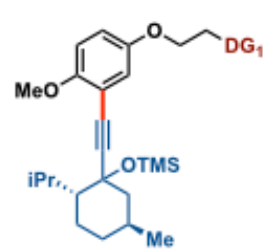

$40,75 \%$

( $m /$ others $>30: 1$ )

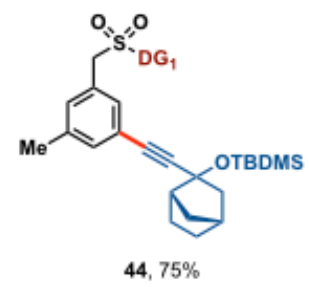

( $m$ /others $12: 1$ )

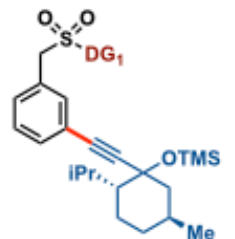

47, $73 \%$

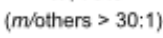

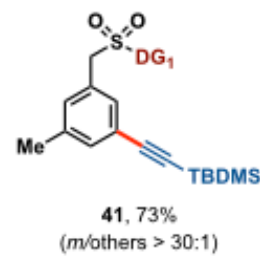

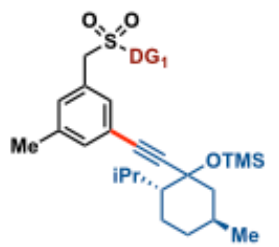

$45,77 \%$

( $m /$ others > 30:1)

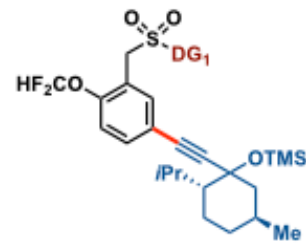

48, $70 \%$ ( $m /$ others > 30:1)

\section{Fig. 4| Scope of the reaction with alkyne variants.}

Further structural diversification of marketed $\mathrm{sp}^{2}$-rich aromatic drugs was achieved through conjugation with $\mathrm{sp}^{3}$-rich $3 \mathrm{D}$-fragments. Both ketoprofen and ibuprofen afforded meta-products conjugated with menthol in excellent yields and $m$-selectivity (58 and 59). Ethinylestradiol, an orally active derivative of estradiol used as estrogen medication, ${ }^{38}$ could selectively be introduced to the meta-position of ketoprofen (60) in preparatively useful yield. The conjugation with aliphatic fragments provides access to an expanded chemical space, escaping the "flatland" of 
aromatic drugs. In principle, this approach could be used to modulate the bioactivity of either parent molecule.

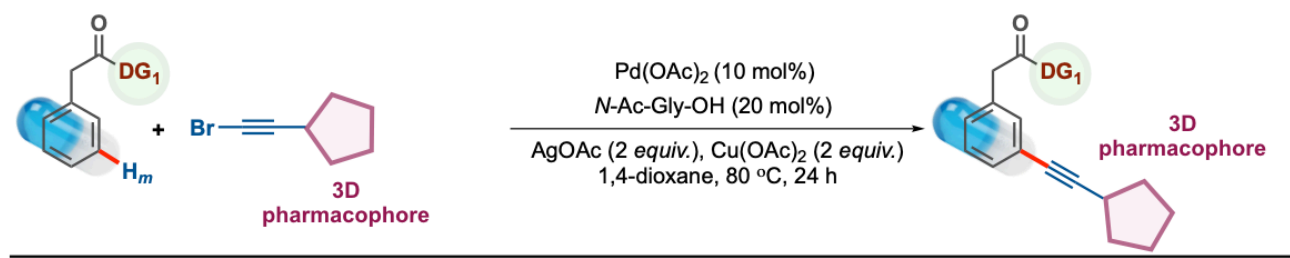

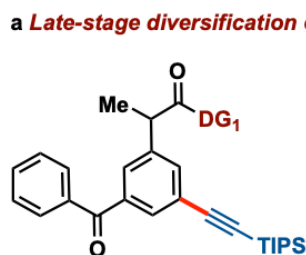

51, $82 \%$ (meta exclusive) from ketoprofen: NSAID

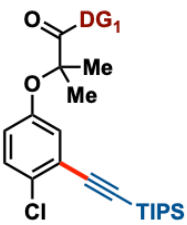

$\mathbf{5 5}, \mathbf{7 7} \%$ (meta exclusive) from clorfibric acid: lipid lowering

b Drug-3D fragment conjugate<smiles>CCCCCCCOC(=O)C(C)c1cc(C#CC2(OC)CC(C)CCC2C(C)C)cc(C(=O)c2ccccc2)c1</smiles>

$58,82 \%$ (meta exclusive) ketoprofen-menthol conjugate menthol: anesthetic

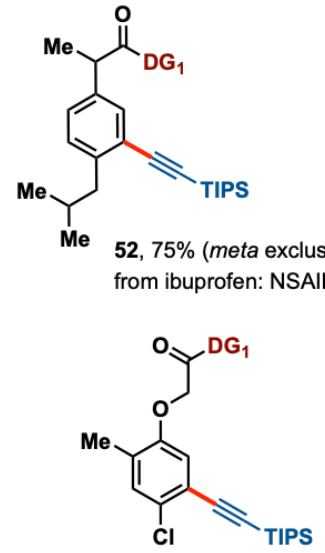

56, $79 \%$ (meta exclusive) from MCPA: herbicide

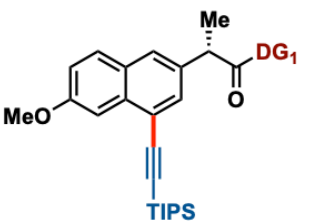

53, $72 \%$ (meta exclusive) $\quad \mathbf{5 4}, \mathbf{7 5} \%$ (meta exclusive) from naproxen: NSAID from dichlorprop: herbicide

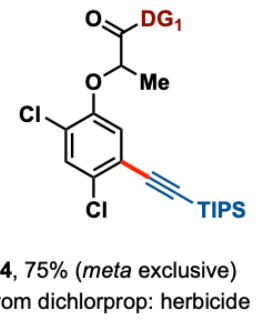

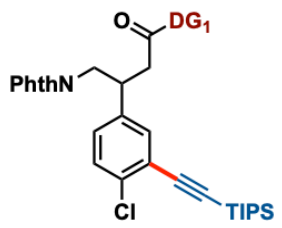

$57,66 \%$ (meta exclusive) from baclophen: NSAID

Fig. 5| Drug diversification. a) Late-stage functionalization of drugs and agrochemicals. b) Drug3D fragment conjugate using alkyne as a linchpin bridge.

Applications of meta-alkynylation protocol. Iterative functionalization at both meta-positions of a benzyl sulfonate ester provides access to further molecular complexity. This sequential process could be carried out with olefination, alkylation and cyanation following reported procedures. The mono-functionalized products underwent alkynylation at vacant meta position to provide heterodifunctionalized products 61-63 (Fig. 6a). Two different alkynes could also be introduced 
iteratively (64). The synthetic utility was further demonstrated by conducting a gram scale reaction that provided an acceptable yield of the product (Fig. 6b). Removal of the directing group under mild conditions affords the parent acid $\mathbf{6 5}$ without affecting the alkyne, demonstrating the practicality of this protocol (Fig. 6c). Finally, the meta-alkynylated benzyl sulfonate ester could be transformed into other functional groups (Fig. 6d). A Julia olefination reaction of $\mathbf{1}$ led to the formation of olefinated product $\mathbf{6 7}$ along with concomitant removal of sulfonate group. A ruthenium catalyzed oxidation of $\mathbf{1}$ gave the corresponding meta-carboxylic acid $\mathbf{6 8}$ by $\mathrm{C}-\mathrm{C}$ bond cleavage while treatment with formic acid under reflux condition afforded the meta-acyl product 69. Furthermore, $\mathrm{CsF}$ enabled desilylation followed by copper catalyzed click reaction with tosylazide gave the meta-triazole product $\mathbf{7 0}$. 

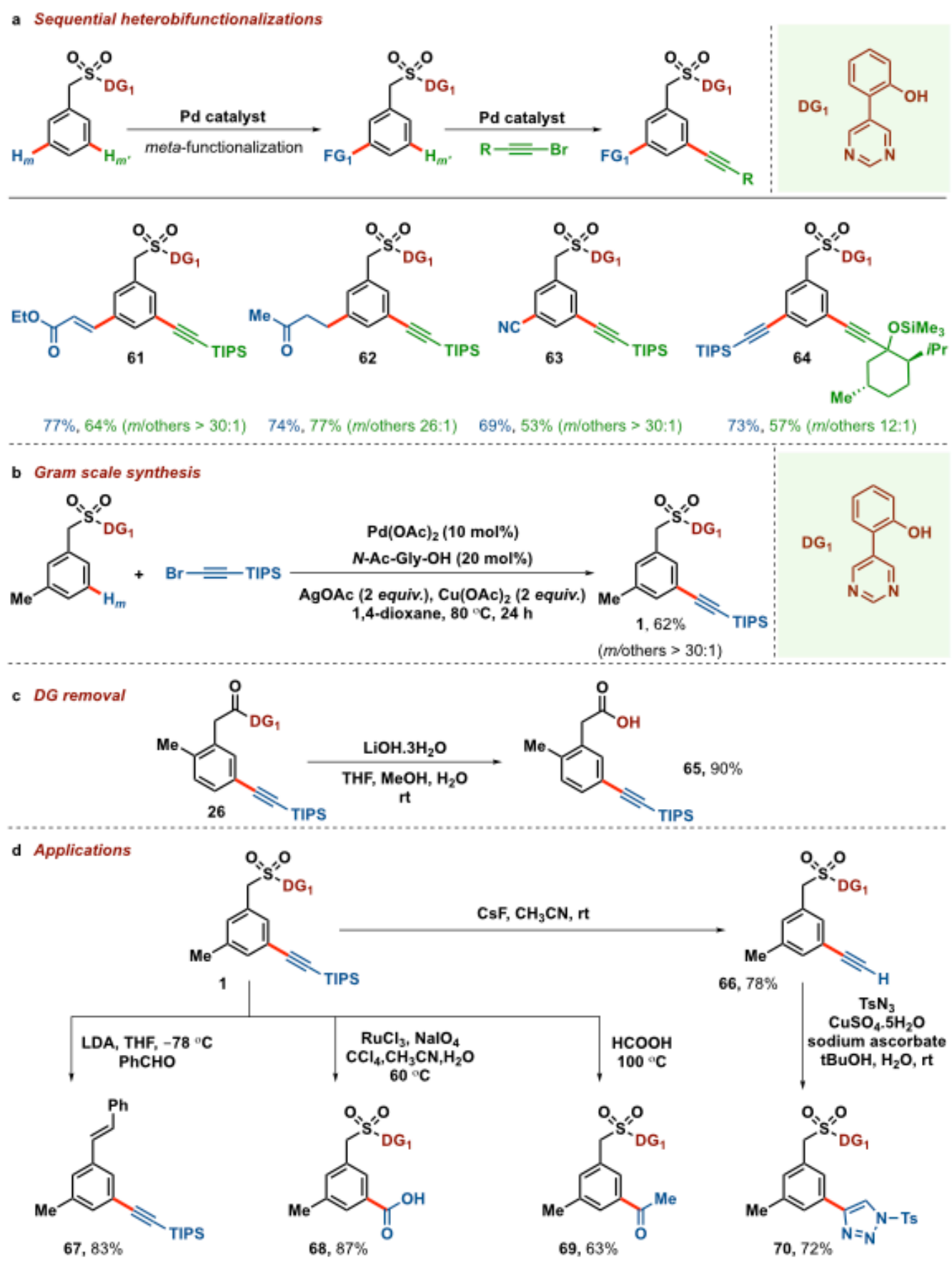

Fig. 6| Applicative potential of meta-alkynylation transformation. a) Sequential metaheterobifunctionalization of arenes. b) Gram scale synthesis of meta-alkynylated product. c) Removal of directing group. d) Synthetic transformation of benzyl sulfonate ester and alkyne functionality.

Mechanistic investigation and computational studies. Kinetic experiments and computational studies were performed to investigate the reaction mechanism. Kinetic isotope effect (KIE) studies 
performed with 1a and its deuterated analogue 1a-D (parallel experiments) gave a value close to unity $\left(k_{\mathrm{H}} / k_{\mathrm{D}}=1.04\right)$ implying $\mathrm{C}-\mathrm{H}$ scission does not occur in the turnover determining transition state (TDTS) of the catalytic cycle (Fig 7a). Furthermore, a first order dependence with respect to both substrate and the alkyne was observed, implicating their involvement in or prior to the TDTS. (Fig 7b).
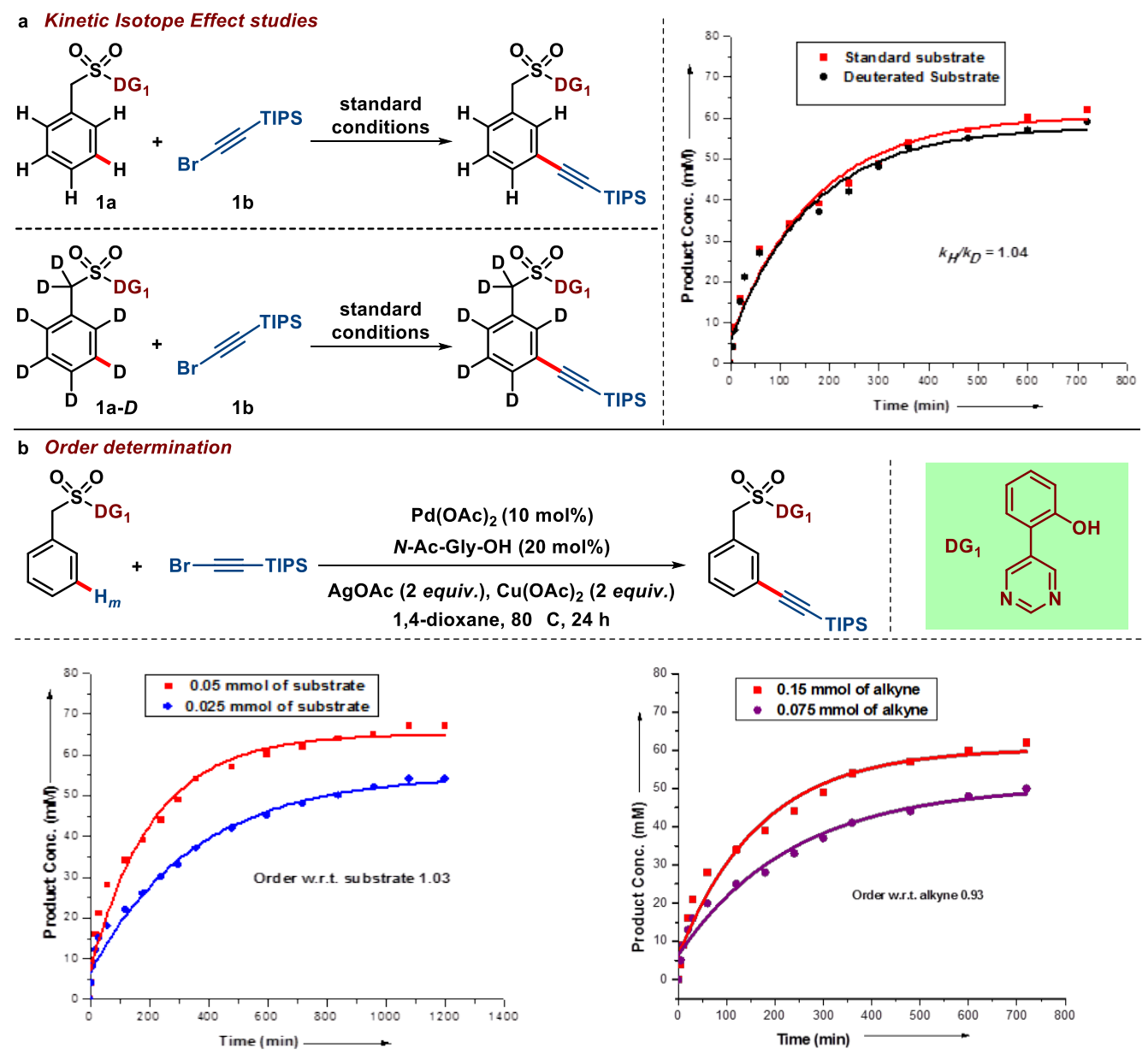

Fig. $7 \mid$ Mechanistic investigation of palladium catalyzed meta $\mathrm{C}-\mathrm{H}$ alkynylation. a, Kinetic isotope effect studies. $\mathbf{b}$, Order determination with respect to substrate and alkyne.

Density functional theory (DFT) calculations were used to rationalize the above observations, and to gain insight into events occurring after the TDTS that do not appear in the experimentally determined rate law. Arene 1a and bromoethynyltrimethylsilane $\mathbf{1 b}$ (hereafter bromoalkyne) were 
considered in these calculations. Gibbs energy profiles were computed at the $\operatorname{SMD}(1,4$-dioxane)$\omega$ B97X-D(MN15)/def2-QZVPP//MN15/GENECP (def2-TZVPPD for Br, Pd and Ag + def2-SVP for others) level of theory. For geometry optimizations a mixed basis set of was used (see SI section 2.6 for full details) $\cdot{ }^{39}$ An abridged Gibbs energy profile showing a full turn of the catalytic cycle is shown in Fig. 8.

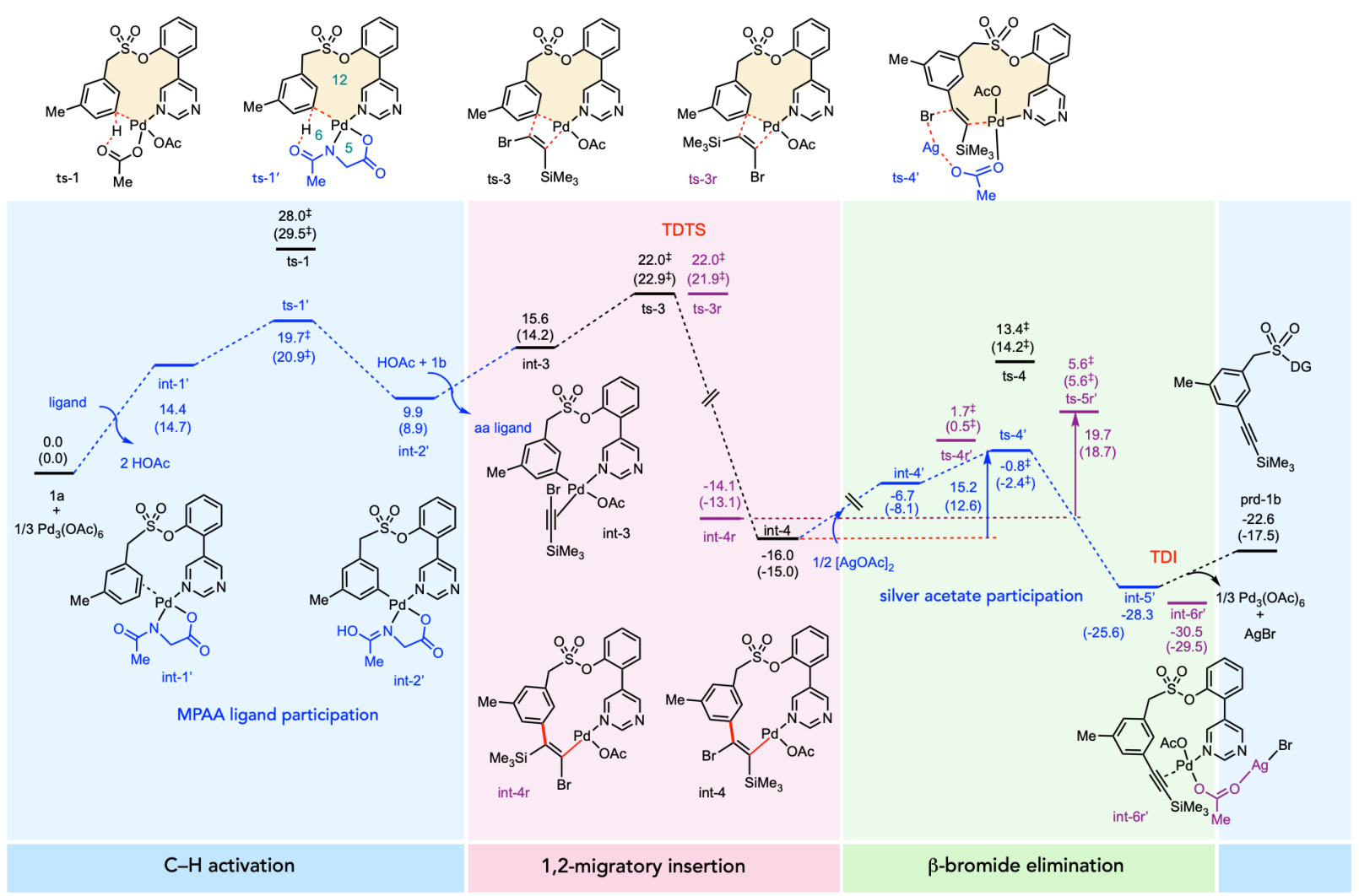

Fig. 8| DFT studies of palladium catalyzed meta $\mathbf{C}-\mathbf{H}$ alkynylation. Computed Gibbs energy profile for $\mathrm{C}\left(s p^{2}\right)-\mathrm{H}$ alkynylation at $80^{\circ} \mathrm{C}$ and standard state of $1 \mathrm{~mol} \mathrm{~L}^{-1}$. Values are given at SMD(1,4-dioxane)- $\omega B$ 97X-D/def2-QZVPPD//MN15/GENECP (def2-TZVPPD for Br, Pd and $\mathrm{Ag}+$ def2-SVP for others) level of theory, with the corresponding MN15 single-point corrected values in parentheses. All values are in $\mathrm{kcal} \mathrm{mol}^{-1}$.

Computed $\mathrm{C}-\mathrm{H}$ activation transition structures (TSs) show a kinetic preference for activation of the meta C-H bond (see SI 2.6.9), by a factor of $41: 1$ over the para position, and $\sim 8000: 1$ over the ortho position. Without a monoprotected amino acid (MPAA) ligand, $\mathrm{C}-\mathrm{H}$ activation has a high 
activation barrier (ts-1, $\left.28.0 \mathrm{kcal} \mathrm{mol}^{-1}\right)$, whereas with MPAA $N$-acetylglycine, ts-1' contains a [5,6]-palladacycle conducive for $\mathrm{C}-\mathrm{H}$ activation, ${ }^{34,40-43}$ lowering the barrier of this step to 19.7 $\mathrm{kcal} \mathrm{mol}^{-1}$. The amide oxygen is strategically positioned for $\mathrm{C}-\mathrm{H}$ activation via Ambiphilic MetalLigand Activation/Concerted Metalation-Deprotonation (AMLA/CMD). Alternative ligand arrangements are uncompetitive (see SI 2.6.3). With the MPAA ligand, $\mathrm{C}-\mathrm{H}$ activation is computed to proceed reversibly before the TDTS, in agreement with the absence of an experimental primary KIE (measured $\left.\mathrm{k}_{\mathrm{H}} / \mathrm{k}_{\mathrm{D}}=1.04\right)$.

1,2-migratory insertion of bromoalkyne $\mathbf{1 b}$ is computed to occur in the turnover frequencydetermining transition state (TDTS) ${ }^{44}$ with a barrier of $22.0 \mathrm{kcal} \mathrm{mol}^{-1}$. The resting state in the catalytic computed catalytic cycle, the turnover determining intermediate (TDI) is the catalyst bound product. Substrate and bromoalkyne both enter the catalytic cycle after this species, consistent with the first order dependence of the rate law on these species' concentrations. (Fig. 7b). The calculations also suggest first order dependence on [MPAA] and inverse first order dependence on [product]. The overall energetic span of the catalytic cycle is $29.9 \mathrm{kcal} \mathrm{mol}^{-1}$, within $2 \mathrm{kcal} / \mathrm{mol}$ of that expected for a reaction taking place over $24 \mathrm{~h}$ at $80^{\circ} \mathrm{C}$.

The alternative mechanism of oxidative addition of $1 \mathrm{c}$ (see SI 2.6.5) breaking the $\mathrm{C}(s p)-\mathrm{Br} \sigma$-bond is uncompetitive at $42.5 \mathrm{kcal} \mathrm{mol}^{-1}$. Migratory insertion is highly exergonic, giving int-4 at -16.0 kcal $\mathrm{mol}^{-1}$. Subsequent $\beta$-bromide elimination, in the absence of silver acetate, has a high activation barrier via ts-4 of $29.4 \mathrm{kcal} \mathrm{mol}^{-1}$; this is lowered to $15.2 \mathrm{kcal} \mathrm{mol}^{-1}$ in its presence, via a $\operatorname{Pd}(\mathrm{II})-\operatorname{Ag}(\mathrm{I})$ heterobimetallic TS (ts-4') shown in Fig. 9. ${ }^{45-47}$ assisted by the enthalpically favourable formation of insoluble $\mathrm{AgBr}$ salt (see SI 2.6.7 for a detailed discussion of the role of the silver acetate additive). Product formation is also favourably exergonic, at $-28.3 \mathrm{kcal} \mathrm{mol}^{-1}$, with respect to the starting materials. 
The migratory insertion step was found to proceed irreversibly with little or no regioselectivity at all (ts-3 and ts-3r, Fig. 8). Interestingly, however, we found that the subsequent steps for each adduct converge to the same silylalkyne product. From int-4, $\beta$-elimination occurs forming the silylalkyne via the anti-periplanar TS, ts-4'. On the other hand, regioisomeric adduct int-4r, undergoes a stepwise loss of bromide (ts-4r', at $1.7 \mathrm{kcal} \mathrm{mol}^{-1} ; \Delta \Delta \mathrm{G}^{\ddagger}=14.1 \mathrm{kcal} \mathrm{mol}^{-1}$ ) and subsequent 1,2-silyl migration (ts-5r', at $5.6 \mathrm{kcal} \mathrm{mol}^{-1} ; \Delta \Delta \mathrm{G}^{\ddagger}=19.7 \mathrm{kcal} \mathrm{mol}^{-1}$ ) to form the sole silylalkyne product. This 1,2-shift occurs as the $\mathrm{Br}$ atom leaves (Fig. 9), gaining negative charge (NBO charge goes from +0.106 in int-4r and +0.045 in int-4r' to -0.312 in ts-4r', -0.501 in int5r' and -0.601 in ts-5r'), while its $\alpha$-carbon gains carbocationic character (NBO charge goes from -0.157 in int-4r and -0.151 in int-4r' to +0.025 in ts- $4 \mathbf{r}^{\prime}$ and +0.097 in int-5r') (SI 2.6.8); anionic $1, n$-silyl migration has been observed in organocopper catalysis, although not previously involving Pd-catalysis. ${ }^{48-50}$ The highest-barrier 1,2-silyl migration ts-5r' after the insertion step has a barrier that is lower than the TDTS (ts-3r) at $22.0 \mathrm{kcal} \mathrm{mol}^{-1}$ and can thus occur efficiently without affecting the overall rate.
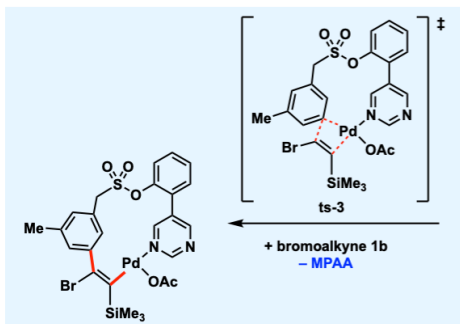

SiMe $_{3}$
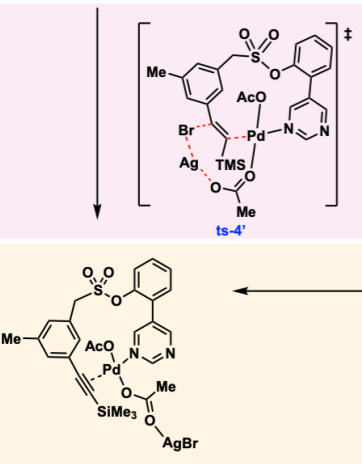
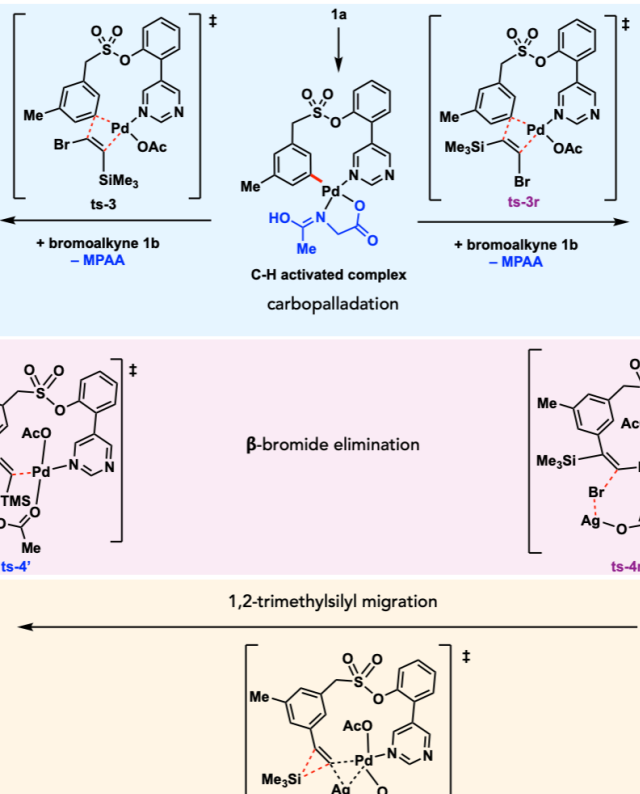

carbopalladation

$\boldsymbol{\beta}$-bromide elimination
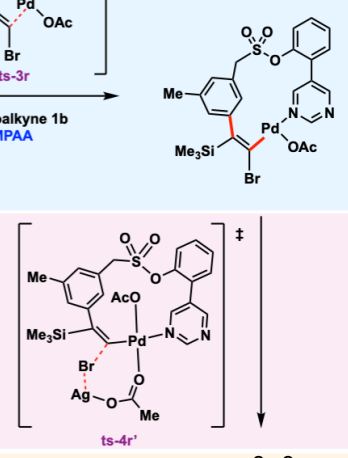

1,2-trimethylsilyl migration

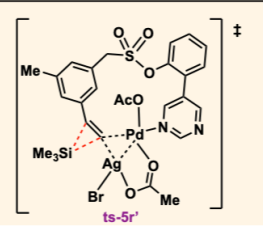

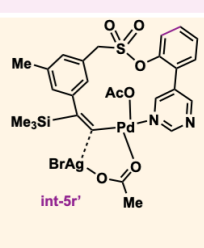
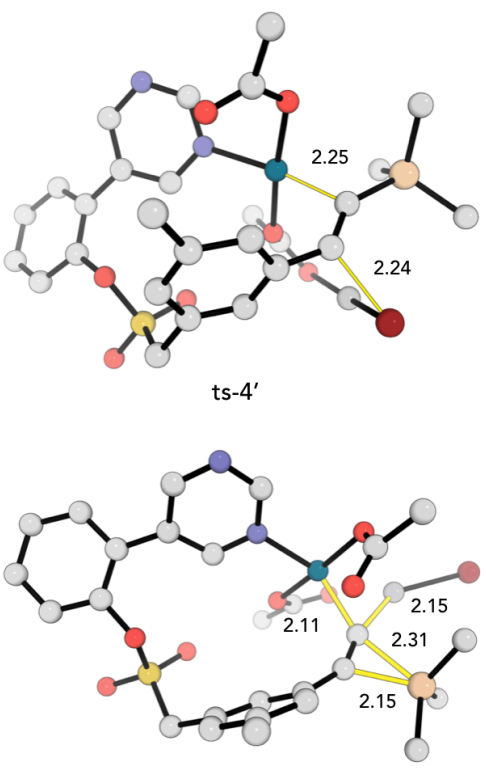

ts-5 $r^{\prime}$ 
Fig. 9| Regioconvergence of C-C bond formation. Carbopalladation occurs unselectively to give regioisomeric vinylsilane intermediates: 1,2-silyl migration can occur, ensuring convergence of both pathways to the same silylalkyne product.

It is noteworthy palladium remains in a formal $\mathrm{Pd}(\mathrm{II})$ oxidation state throughout the catalytic cycle, as opposed to a $\operatorname{Pd}(\mathrm{II}) / \mathrm{Pd}(\mathrm{IV})$ manifold. The role of copper(II) acetate was explored computationally (SI 2.6.12). We found that the $\mathrm{Pd}(\mathrm{II})-\mathrm{Cu}(\mathrm{II})$ heterobimetallic TS (ts-4'-Cu, 7.3 kcal mol${ }^{-1}$, Fig. S17b) gives an overall barrier of $23.3 \mathrm{kcal} \mathrm{mol}^{-1}, 8.1 \mathrm{kcal} \mathrm{mol}^{-1}$ higher than the Pd(II)-Ag(I) heterobimetallic TS (ts-4', $\left.-0.8 \mathrm{kcal} \mathrm{mol}^{-1}\right)$. The $\mathrm{Pd}(\mathrm{II})-\mathrm{Cu}(\mathrm{II})$ heterobimetallic TS for the regioisomeric rate-determining silyl group migration (ts-5r'-Cu, $27.9 \mathrm{kcal} \mathrm{mol}^{-1}$ ) also has a higher barrier than the $\mathrm{Pd}(\mathrm{II})-\mathrm{Ag}(\mathrm{I})$ heterobimetallic TS (ts-5r', $\left.5.6 \mathrm{kcal} \mathrm{mol}^{-1}\right)$. Coordination to the product releases the palladium catalyst for the next cycle. This transmetalation is more thermodynamically favourable than the direct release of product from int-5' (Fig. S19), suggesting that it could aid catalyst turnover after each catalytic cycle. The reduced copper co-oxidant, $\mathrm{Cu}(\mathrm{I})$, could lower the activation barrier of the $\beta$-bromide elimination (ts-4'-Cu-I, $-2.7 \mathrm{kcal} \mathrm{mol}^{-1}$, Fig. S17), potentially contributing to an enhanced yield.

\section{Conclusions}

In summary, we have developed a strategy for meta-selective $\mathrm{C}-\mathrm{H}$ alkynylation in which the alkyne plays a linchpin role coupling $\mathrm{sp}^{2}$ and $\mathrm{sp}^{3}$-rich fragments. A diverse variety of substrates including benzyl sulfonate esters, phenyl acetic acids, benzyl silyl ethers and elongated alkyl ethers can be conjugated with aliphatic fragments. This transformation enables site-selective late stage functionalization of $\alpha$-amino acids, marketed drugs and agrochemicals with the addition of bioactive $3 \mathrm{D}$-fragments and natural products. It is also possible to convert the alkyne functionality to other functional groups. Mechanistic investigations suggest that the present Pd-catalyzed meta- 
selective $\mathrm{C}\left(s p^{2}\right)-\mathrm{H}$ alkynylation proceeds via 1,2-migratory insertion, followed by $\beta$-bromide elimination rather than commonly observed oxidative addition/reductive elimination reaction mode. 1,2-migratory insertion was found to be the overall turnover limiting transition state, which occurs after relatively rapid and reversible meta $\mathrm{C}-\mathrm{H}$ activation, in agreement with experimental kinetic isotope effects and the measured rate law. 1,2-migratory insertion occurs irreversibly, producing both regioisomers. Regioconvergence towards the final product is ensured by 1,2migration of the trialkylsilyl group following $\beta$-bromide elimination.

\section{Methods:}

\section{General procedure for palladium catalyzed meta-selective $\mathrm{C}-\mathrm{H}$ alkynylation of arene: A}

clean, oven-dried screw cap reaction tube with previously place magnetic stir-bar was charged with sulfonate ester ( $0.1 \mathrm{mmol}, 1$ equiv.), $\mathrm{Pd}(\mathrm{OAc})_{2}$ (10 mol\%), Ac-Gly-OH (20 mol\%), AgOAc (2.0 equiv.), $\mathrm{Cu}(\mathrm{OAc})_{2}$ (2 equiv.). It was then followed by addition of (bromoethynyl)triisopropylsilane (2.5 equiv.) and 1,4-dioxane $(1 \mathrm{~mL})$. The reaction mixture was vigorously stirred in a preheated oil bath at $80{ }^{\circ} \mathrm{C}$ for $24 \mathrm{~h}$. After stipulated time, the reaction mixture was cooled to room temperature and filtered through a celite bed using ethyl acetate as the eluent $(30 \mathrm{~mL})$. The filtrate was concentrated and the crude reaction mixture was purified by column chromatography using silica gel (100-200 mesh size) and petroleum-ether / ethyl acetate as the eluent.

Data availability: Experimental procedures, analytical data $\left({ }^{1} \mathrm{H},{ }^{13} \mathrm{C}\right.$ NMR, MS), computational methodologies, raw atomic values of optimized structures are available in the Supplementary Information. Cartesian coordinates ( $x y z$ format) for all stationary points are deposited online at DOI:10.5281/zenodo.3376707). 


\section{References}

1. J.-Q. Yu \& Shi, Z. (eds) C-H Activation Vol. 26 (Topics in Current Chemistry, Springer, New York, 2010).

2. Ribas, X. (eds) $C-H$ and $C-X$ Bond Function: Transition Metal Mediation (RSC Publishing, London, 2013).

3. Yamaguchi, J., Yamaguchi, A. D. \& Itami, K. C-H bond functionalization: emerging synthetic tools for natural products and pharmaceuticals. Angew. Chem. Int. Ed. 51, 8960-9009 (2012).

4. Abrams, D. J., Provencher, P. A., \& Sorensen, E. J. Recent applications of C-H functionalization in complex natural product synthesis. Chem. Soc. Rev. 47, 8925-8967 (2018).

5. Liu, Y. \& Ge. H. Site-selective C-H arylation of primary aliphatic amines enabled by a catalytic transient directing group. Nat. Chem. 9, 26-32 (2016).

6. Boström, J., Brown, D. G., Young, R. J. \& Keserü, G. M. Expanding the medicinal chemistry synthetic toolbox. Nat. Rev. Drug Discov. 17, 709-727 (2018).

7. Wencel-Delord, J. \& Glorius, F. C-H bond activation enables the rapid construction and latestage diversification of functional molecules. Nat. Chem. 5, 369-375 (2013).

8. Cernak, T., Dykstra, K. D., Tyagarajan, S., Vachalb, P. \& Krskab, S. W. The medicinal chemist's toolbox for late stage functionalization of drug-like molecules. Chem. Soc. Rev. 45, 546$576(2016)$

9. Hann, M. M. \& Keserü, G. M. Finding the sweet spot: the role of nature and nurture in medicinal chemistry. Nat. Rev. Drug Discov. 11, 355-365 (2012). 
10. Busacca, C. A., Fandrick, D. R., Song, J. J. \& Senanayake, C. H. in Applications of Transition Metal Catalysis in Drug Discovery and Development: An Industrial Perspective (eds Crawley, M. L. \& Tost, B. M.) 1-25 (Wiley, New York, 2012).

11. Dai, H.-X., Stepan, A. F., Plummer, M. S., Zhang, Y.-H. \& Yu, J.-Q. Divergent C-H functionalizations directed by sulfonamide pharmacophores: late-stage diversification as a tool for drug discovery. J. Am. Chem. Soc. 133, $7222-7228$ (2011).

12. Simonetti, M., Cannas, D. M., Just-Baringo, X., Vitorica-Yrezabal, I. J. \& Larrosa, I. Cyclometallated ruthenium catalyst enables late-stage directed arylation of pharmaceuticals. Nat. Chem. 10, 724-731 (2018).

13. Dey, A., Sinha, S. K., Achar, T. K. \& Maiti, D. Accessing remote meta- and para-C-H bonds with covalently attached directing groups. Angew. Chem. Int. Ed. 58, 10820-10843 (2019).

14. Wang, J. \& Dong, G. Palladium/norbornene cooperative catalysis. Chem. Rev. 119, 7478-7528 (2019).

15. Leitch, J. A. \& Frost. C. G. Ruthenium-catalysed $\sigma$-activation for remote meta-selective C-H functionalisation. Chem. Soc. Rev. 46, 7145-7153 (2017).

16. Mihai, M. T., Genov, G. R. \& Phipps, R. J. Access to the meta position of arenes through transition metal catalysed $\mathrm{C}-\mathrm{H}$ bond functionalisation: a focus on metals other than palladium. Chem. Soc. Rev. 47, 149-171 (2018).

17. Leow, D., Li, G., Mei, T.-S. \& Yu, J.-Q. Activation of remote meta-C-H bonds assisted by an end-on template. Nature 486, 518-522 (2012).

18. Tobisu, M. \& Chatani, N. Remote control by steric effects. Science 343, 850-851 (2014). 
19. Davis, H. J., Mihai, M. T. \& Phipps, R. J. Ion pair-directed regiocontrol in transition-metal catalysis: a meta-selective $\mathrm{C}-\mathrm{H}$ borylation of aromatic quaternary ammonium salts. J. Am. Chem. Soc.138, 12759-12762 (2016).

20. Ruan, Z., Zhang, S.-K., Zhu, C., Ruth, P. N., Stalke, D. \& Ackermann, L. Ruthenium(II)catalyzed meta $\mathrm{C}-\mathrm{H}$ mono- and difluoromethylations by phosphine/carboxylate cooperation. Angew. Chem. Int. Ed. 56, 2045-2049 (2017).

21. Bag, S., Patra, T., Modak, A., Deb, A., Maity, S., Dutta, U., Dey, A., Kancherla, R., Maji, A., Hazra, A., Bera, M. \& Maiti, D. Remote para-C-H functionalization of arenes by a D-shaped biphenyl template-based assembly. J. Am. Chem. Soc. 137, 11888-11891 (2015).

22. Brown, D. G. \& Boström, J. Analysis of past and present synthetic methodologies on medicinal chemistry: where have all the new reactions gone? J. Med. Chem. 59, 4443-4458 (2016).

23. Fosgerau, K. \& Hoffmann, T. Peptide therapeutics: current status and future directions. Drug Discov. Today 20, 122-128 (2015).

24. Trofimov, B. A., Stepanova, Z. V., Sobenina, L. N., Mikhaleva, A. I. \& Ushakov, I. A. Ethynylation of pyrroles with 1-acyl-2-bromoacetylenes on alumina: A formal "inverse Sonogashira coupling." Tetrahedron Lett. 45, 6513-6516 (2004).

25. Acetylene Chemistry: Chemistry, Biology and Material Science; Diederich, F., Stang, P. J., Tykwinski, R. R., Eds.; Wiley-VCH: Weinheim, Germany, 2005.

26. Tobisu, M., Ano, Y. \& Chatani, N. Palladium-catalyzed direct alkynylation of C-H Bonds in benzenes. Org. Lett. 11, 3250-3252 (2009).

27. Viart, H. M.-F., Bachmann, A., Kayitare, W. \& Sarpong, R. $\beta$-Carboline amides as intrinsic directing groups for $\mathrm{C}\left(\mathrm{sp}^{2}\right)-\mathrm{H}$ functionalization. J. Am. Chem. Soc. 139, 1325-1329 (2017). 
28. Ruan, Z., Sauermann, N., Manoni, E. \& Ackermann, L. Manganese-catalyzed C-H alkynylation: expedient peptide synthesis and modification. Angew. Chem. Int. Ed. 56, 3172-3176 (2017).

29. Tan, E., Quinonero, O., de Orbe, M. E. \& Echavarren, A. M. Broad-scope Rh-catalyzed inverse-Sonogashira reaction directed by weakly coordinating groups. ACS Catal. 8, 2166-2172 (2018).

30. A meta-selective alkynylation was achieved using Catellani approach, however substrate scope was limited to silyl acetylenic derivatives. Wang, P., Li, G.-C., Jain, P., Farmer, M. E., He, J., Shen, P.-X. \& Yu, J.-Q. Ligand-promoted meta-C-H amination and alkynylation. J. Am. Chem. Soc. 138, 14092-14099 (2016).

31. Brand, J. P. \& Waser, J. Para-selective gold-catalyzed direct alkynylation of anilines. Org. Lett. 14, 744-747 (2012).

32. Bag, S., Jayarajan, R., Mondal, R. \& Maiti, D. Template-assisted meta-C-H alkylation and alkenylation of arenes. Angew. Chem. Int. Ed. 56, 3182-3186 (2017).

33. Bag, S., Jayarajan, R., Dutta, U., Chowdhury, R., Mondal, R. \& Maiti, D. Remote meta-C-H cyanation of arenes enabled by a pyrimidine-based auxiliary. Angew. Chem. Int. Ed. 56, 1253812542, (2017).

34. Achar, T. K., Zhang, S., Mondal, R., Shanavas, M, S., Maiti, S., Maity, S., Pal, N., Paton, R. S. \& Maiti, D. Palladium-catalyzed directed meta-selective $\mathrm{C}-\mathrm{H}$ allylation of arenes: unactivated internal olefins as allyl surrogates. Angew. Chem. Int. Ed. 58, 10353-10360 (2019).

35. Negishi, E. \& Anastasia, A. Palladium-catalyzed alkynylation. Chem. Rev. 103, 1979-2017 (2003). 
36. Sinha, S. K., Bhattacharya, T. \& Maiti, D. Role of hexafluoroisopropanol in C-H activation. React. Chem. Eng. 4, 244-253 (2019).

37. Reddy, D. S. \& Jian, K._The testosterone-derived neurosteroid androstanediol is a positive allosteric modulator of GABAA receptors. J. Pharmacol. Exp. Ther. 334, 1031-1041 (2010).

38. Kuhl, H. Pharmacology of estrogens and progestogens: influence of different routes of administration. Climacteric. 8, 3-63 (2005).

39. Frisch, M. J., Trucks, G. W., Schlegel, H. B., Scuseria, G. E., Robb, M. A., Cheeseman, J. R., Scalmani, G., Barone, V., Mennucci, B., Petersson, G. A., et al. Gaussian 16, Revision A.01. 2016. 40. Chen, G., Gong, W., Zhuang, Z., Andrä, M. S., Chen, Y. Q., Hong, X., Yang, Y. F., Liu, T., Houk, K. N. \& Yu, J. Q. Ligand-accelerated enantioselective methylene C( $\left.\mathrm{sp}^{3}\right)-\mathrm{H}$ bond activation. Science 353, 1023-1027 (2016).

41. Cheng, G. J., Yang, Y. F., Liu, P., Chen, P., Sun, T. Y., Li, G., Zhang, X., Houk, K. N., Yu, J. Q. \& Wu, Y. D. Role of $N$-acyl amino acid ligands in $\mathrm{Pd}(\mathrm{II})$-catalyzed remote $\mathrm{C}-\mathrm{H}$ activation of tethered arenes. J. Am. Chem. Soc. 136, 894-897 (2014).

42. Yang, Y. F., Hong, X., Yu, J. Q. \& Houk, K. N. Experimental-computational synergy for selective Pd(II)-catalyzed C-H activation of aryl and alkyl groups. Acc. Chem. Res. 50, 2853-2860 (2017).

43. Dutta, U., Modak, A., Bhaskararao, B., Bera, M., Bag, S., Mondal, A., Lupton, D. W., Sunoj, R. B. \& Maiti, D. Catalytic arene meta-C-H functionalization exploiting a quinoline-based template. ACS Catal. 7, 3162-3168 (2017).

44. Kozuch, S. \& Shaik, S. How to conceptualize catalytic cycles? the energetic span model. Acc. Chem. Res. 44, 101-110 (2011).

45. Yang, Y. F., Cheng, G. J., Liu, P., Leow, D., Sun, T. Y., Chen, P., Zhang, X., Yu, J. Q., Wu, 
Y. D. \& Houk, K. N. Palladium-catalyzed meta-selective C-H bond activation with a nitrilecontaining template: computational study on mechanism and origins of selectivity. J. Am. Chem. Soc. 136, 344-355 (2014).

46. Anand, M., Sunoj, R. B. \& Schaefer, H. F. Non-innocent additives in a palladium(II)-catalyzed $\mathrm{C}-\mathrm{H}$ bond activation reaction: insights into multimetallic active catalysts. J. Am. Chem. Soc. 136, 5535-5538 (2014).

47. Guin, S., Dolui, P., Zhang, X., Paul, S., Singh, V. K., Pradhan, S., Chandrashekar, H. B., Anjana, S. S., Paton, R. S. \& Maiti, D. Iterative arylation of amino acids and aliphatic amines via $\delta-\mathrm{C}\left(\mathrm{sp}^{3}\right)-\mathrm{H}$ activation: experimental and computational exploration. Angew. Chem. Int. Ed. 58, 5633-5638 (2019).

48. Taguchi, H., Miyashita, H., Tsubouchi, A. \& Takeda, T. First anionic silyl migration from $\mathrm{sp}^{2}$ carbon to carbonyl oxygen. stereospecific allylation of (Z)- $\beta$-trimethylsilyl- $\alpha, \beta$-unsaturated ketones. Chem. Commun. 2002, 2 (19), 2218-2219.

49. Tsubouchi, A., Sasaki, N., Enatsu, S. \& Takeda, T. Regio- and stereoselective preparation of (Z)-silyl enol ethers by three-component coupling using $\alpha, \beta$-unsaturated acylsilanes as core building blocks. Tetrahedron Lett. 54, 1264-1267 (2013).

50. Tsubouchi, A., Matsuda, H., Kira, T. \& Takeda, T. Silyl migration in conjunction with substitution on silicon in copper(I) t-butoxide-promoted coupling between o-silylphenyl ketones and organic halides. Chem. Lett. 38, 1180-1181 (2009).

\section{Acknowledgements}

We are thankful to SERB-India (CRG/2018/003951) for financial support. Funding from A*STAR Singapore (X.Z.) is gratefully acknowledged. X.Z. and R.S.P. acknowledge the EPSRC Centre for 
Doctoral Training in Theory and Modelling in Chemical Sciences (EP/L015722/1) and the use of Dirac cluster. R.S.P. acknowledges computational resources from the RMACC Summit supercomputer supported by the National Science Foundation (ACI-1532235 and ACI-1532236), the University of Colorado Boulder and Colorado State University, and the Extreme Science and Engineering Discovery Environment (XSEDE) through allocation TG-CHE180056. XSEDE is supported by the National Science Foundation (ACI-1548562).

\section{Author contributions}

S.G. and S.P. conceived and developed the palladium catalyzed meta-selective $\mathrm{C}-\mathrm{H}$ alkynylation. S.P. optimized the reaction conditions. S.G., S.P., S.B., and V.K.S. prepared the starting materials and identified the substrates scope. S.P. conducted the mechanistic investigations. X.Z. designed and performed the computational studies. R.S.P supervised the computational studies. D.M. supervised the project. S.G., S.P., X.Z., R.S.P. and D.M. prepared the manuscript.

\section{Competing interests}

The authors declare no competing interests. 


\section{TOC GRAPHIC}

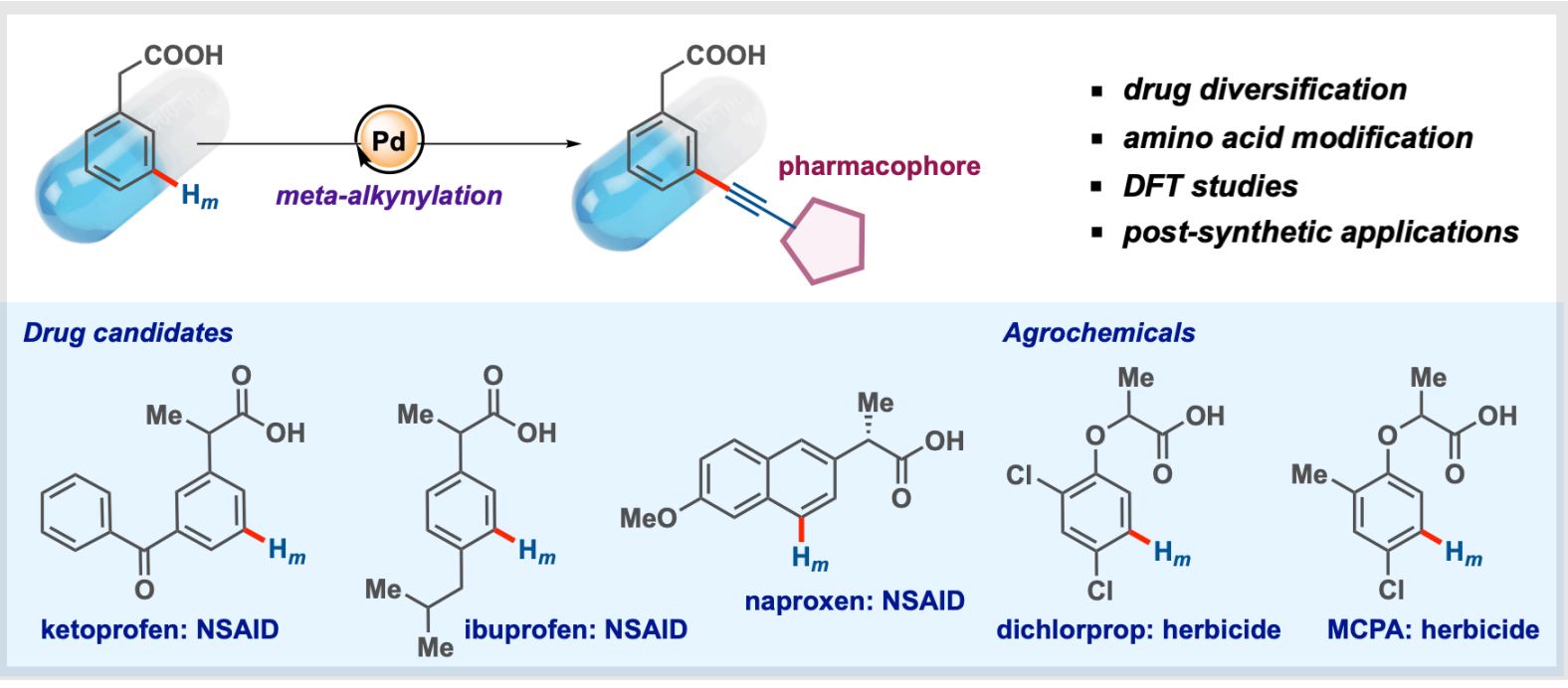

